\title{
Plate-like Buckling Resistance of Longitudinally Stiffened Plates Subjected to Pure Compression
}

\author{
Balázs Kövesdi* \\ 1 Department of Structural Engineering, \\ Faculty of Civil Engineering, \\ Budapest University of Technology and Economics, \\ H-1111 Budapest, Műegyetem rkp. 3. K.mf. 85., Hungary \\ *Corresponding author, e-mail: kovesdi.balazs@epito.bme.hu
}

Received: 04 December 2018, Accepted: 08 April 2019, Published online: 08 May 2019

\begin{abstract}
Plate buckling resistance calculation of orthotropic plates and the determination of the effective width is highly important in the design of bridges. The current effective width calculation method provided by the EN 1993-1-5 [1] is developed for I-sections subjected to bending. Previous research results proved that the application of the plate buckling curve can overestimate the buckling resistance in case of square box sections subjected to pure compression. It means, that the required safety level of the Eurocode is not fulfilled for buckling resistance of plates in compression. Several previous studies proved the unconservatism of the EN 1993-1-5 for this special case, where the plate has no support coming from the adjacent plates. The question arises, if the above mentioned calculation process also leads to unsafe resistances for other structural details, or this is the specialty of the analyzed worst case scenario. Longitudinally stiffened plates (bottom flange of steel box sections) subjected to pure compression could be also a worst case scenario, because they are not supported by adjacent plates and they are loaded by pure compression. Therefore, the current research focuses on the investigation of longitudinally stiffened orthotropic plates loaded by pure compression and investigates (1) the plate-like buckling resistance, (2) the applicability of the Winter curve and (3) determines the necessary partial safety factor according to the safety requirements of the Eurocode. In the present paper the results of an extensive numerical research program are introduced and the applicability of the Winter curve is evaluated based on the safety requirements of the Eurocode.
\end{abstract}

\section{Keywords}

plate buckling, orthotropic plates, closed section stiffeners, partial safety factor

\section{Introduction}

In case of steel bridges, one of the most common structural layout is the orthotropic plate. The failure mode of these plates depends on the plate-like and column-like behavior. Plate-like behavior is dominant, if the ultimate shape has significant curvature in both directions. Column-like behavior is dominant, if the failure mode has dominant curvature only in one direction, which can be the typical failure mode in case of plates with small length-to-width aspect ratio $(\alpha=a / b<1)$ or having strong stiffeners. The dominant behavior depends on the lengthto-width ratio of the plate $(\alpha)$ and on the stiffener stiffness compared to the out-of-plane stiffness of the plate $(\gamma)$ [2]. The typical failure modes representing plate-like and column-like behavior are shown in Fig. 1.

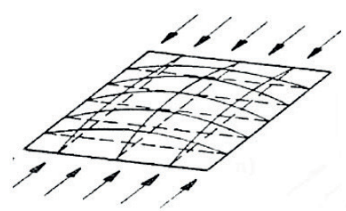

a) plate-like behavior [2]

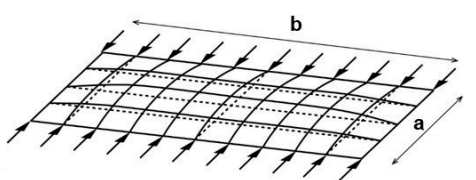

b) column-like behavior [1]
Fig. 1 Typical structural behavior for stiffened plates under compression

In case of bridges the most common failure mode is the interaction type failure, because pure plate or pure column-like behavior requires special boundary conditions or panel geometries. However, the resistance is calculated based on the pure plate and column-like behavior using an interpolation formula (Eqs. (1) and (2)), which considers the reduction factors related to the column-like and plate-like buckling. 
$\rho_{c}=\left(\rho-\chi_{c}\right) \cdot \xi \cdot(2-\xi)+\chi_{c}$,

where

$\xi=\frac{\sigma_{c r, p}}{\sigma_{c r, c}}-1$, but $0 \leq \xi \leq 1$.

$\sigma_{c r, p}$ and $\sigma_{c r, c}$ are elastic critical plate and column buckling stresses,

$\chi_{c}$ is reduction factor due to pure column-like buckling, $\rho$ is reduction factor due to pure plate-like buckling.

There are numerous investigations studying the applicability of this interpolation function [2-5]. However, the applicability also depends on the reliability of the resistances which are used for the interpolation. Therefore, the investigation of the pure plate-like behavior and the evaluation of the plate buckling resistance is an important point of the design process, which has not been widely investigated in the past according to the author's knowledge.

On the other side, previous research results [6-8] showed that the required safety level of the Eurocode is not reached by using the formula of the EN 1993-1-5 [1] for local buckling resistance of box section columns. Schillo et al. [7] proposed a new buckling curve or an increased partial safety factor for plate buckling resistance of plates loaded by pure compression and not supported by adjacent plates (for example: square box section columns). The situation of longitudinally stiffened lower flange of box section steel bridges are more or less in the same situation which are reported by Schillo et al. [7]. However, they studied only the buckling behavior of unstiffened plates. The current investigation extends these studies to longitudinally stiffened panels using closed section stiffeners, as shown in Fig. 2.

The aim of the current research work is to (i) perform a comprehensive numerical study on the pure plate-like buckling resistance of orthotropic plates using closed section longitudinal stiffeners and (ii) to check the applicability of the plate buckling curve of the EN 1993-1-5. Numerical model is developed to reach these research aims and more than 80 numerical simulations are executed covering large parameter range of girder geometries with diverse longitudinal stiffener configurations. Within the current research program only geometries having dominant plate-like behavior are studied. Plate-like behavior is checked based on the classification methodology of the EN $1993-1-5 ; \xi$ value of the analyzed panels are always larger than 1,5 . The research work is completed according to the following research strategy:
- literature review of the previous investigations,

- development and validation of an advanced numerical model made of shell elements with various geometry and different longitudinal stiffener confi-gurations,

- numerical parametric study to determine the buckling resistance of the stiffened panels,

- determination of the necessary partial safety factor according to EN 1990 [9].

\section{Literature review}

Large number of previous investigation were made in the last 50 years on the buckling resistance of longitudinally unstiffened and stiffened plates. The research on buckling behavior of unstiffened panels was started by Kármán [10], Timoshenko [11] and Winter [17], which research results are mainly implemented in design codes. Stability of longitudinally stiffened panels is also a widely researched topic started by Klöppel and Scheer [12] and Klöppel and Möller [13]. The first research results are made on panels having open section longitudinal stiffeners, where the torsional stiffness has negligible effect on the buckling behavior.

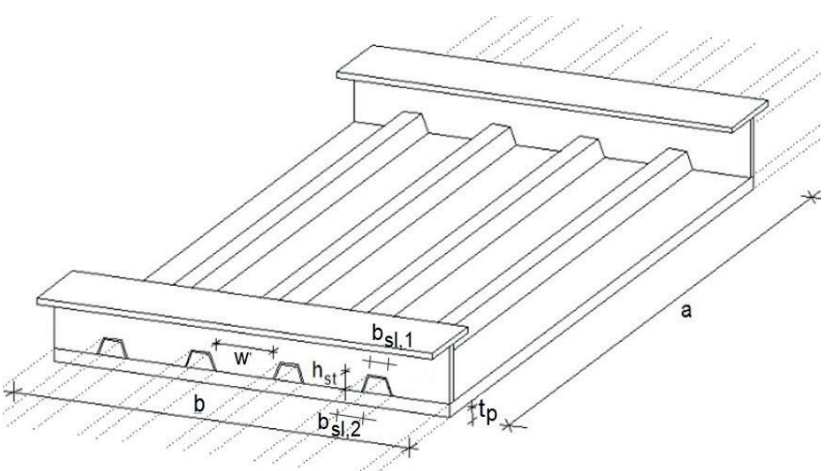

a)

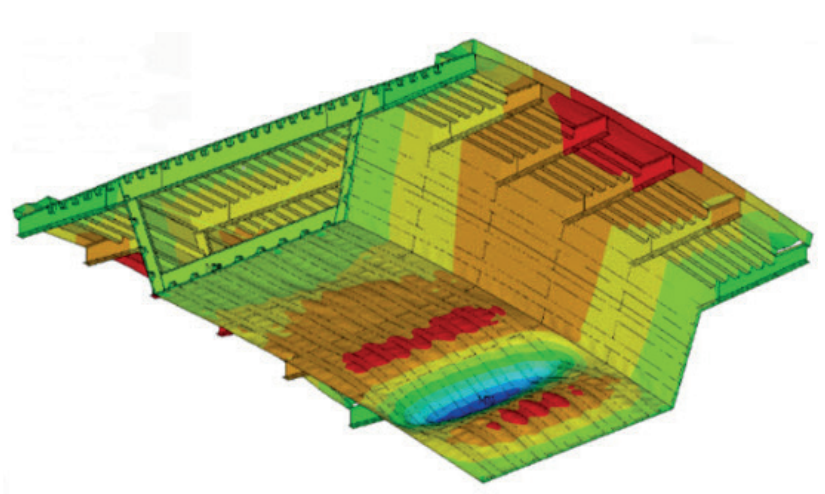

b)

Fig. 2 a) Longitudinally stiffened lower flange of a box section bridge with used notations and b) demonstration of optional failure mode 
Experimental research programs are also executed on large scale test specimens within the last 20-30 years on the determination of the plate buckling resistance. Yamada and Watanabe [14] and Mikami and Niwa [15] made extensive experimental research in this topic and developed design methods for the buckling resistance check of stiffened panels. However, these design methods are not compatible with the Eurocode based design of orthotropic panels. Numerical investigations are also made by Simon et al. [16] in 2014 investigating the optimum stiffener size considering the column and plate-like behavior. Significant experimental and numerical research program has been executed in frame of the COMBRI RFCS Research Project [2] in cooperation of several European Universities and Research Centers. The main aim of these investigations was to check the Eurocode based design method related to the column-like and plate-like buckling behavior and to check the applicability of the interpolation curve. Based on the numerical calculations improvement proposals are formulated regarding the stiffened panels using open section stiffeners. Numerical research program has been conducted in 2017 by Martin et al. [3] investigating stiffened panels having closed section stiffeners. Numerical simulation results proved that stiffeners with flexural rigidity of $\gamma_{s l} \leq 25$ according to EN 1993-1-5 (where $\gamma_{s l}$ is the relative stiffness of one stiffener) should not be considered in the design process and the torsional stiffness of closed section stiffeners should be neglected in the calculation of the critical plate buckling stress. However, it should be mentioned that the geometries studied in the previous research programs were mainly focusing on the interaction between the plate and column-like behavior. However, the pure plate-like buckling behavior was not investigated or not evaluated separately for stiffened panels based on the author's knowledge.

The plate buckling curve of the EN 1993-1-5 [1] is based on the effective width method derived by Kármán et al. [10] in 1932. Winter semi-empirically improved this method and developed the Winter curve in 1947 [17], which has been slightly modified several times based on experimental results. The formula given by Eq. 3 is currently used by the EN1993-1-5 for pure compression, which is identical by the original Winter curve.

$\rho=\frac{b_{e f f}}{b}=\frac{1}{\bar{\lambda}_{p}} \cdot\left(1-\frac{0.22}{\bar{\lambda}_{p}}\right), \bar{\lambda}_{p} \geq 0.673$,

where: $b$ is width of the plate,

$b_{\text {eff }}$ is effective width of the plate,

$\bar{\lambda}_{p}$ is the relative slenderness ratio for plate buckling.
The accuracy of this curve was questioned by several researchers in the past. In 1987 Scheer compared the Winter curve to experimental results and concluded that it provides the mean value of the test results. In 1998 and 2002 Bridge and O'Shea [18, 19] tested welded box sections and the test results also gave lower resistances than provided by the Winter curve. Schillo et al. [6-8] executed an experimental and numerical research program to study the local buckling resistance of square box section columns made of normal and high strength steel. The results were compared to the Winter curve. The comparison showed that significant number of test results gave smaller resistances than provided by the standard design method. Conclusion of Schillo et al. [7-8] was that Winter curve provides the mean value of the test results, and the required safety level of the EN 1990 [9] cannot be achieved by using a partial safety factor $\gamma_{M 1}=1,0$. Statistical evaluation also proved that even $\gamma_{M 1}=1,1$ would underestimate the necessary safety level.

Based on the literature review it can be concluded that despite the large number of previous investigation related to the plate buckling behavior of longitudinally unstiffened and stiffened panels, a comprehensive study evaluating the pure plate buckling behavior of longitudinally stiffened girders are still missing from the international literature. The research work of Schillo et al. [6-8] focused only on unstiffened plates and all the previous research activities on stiffened panels were focusing on the interpolation between the plate and column-like behavior. Therefore, the current investigation focuses on the plate buckling resistance of longitudinally stiffened girders having closed section stiffeners, which have dominant plate-like behavior.

\section{Numerical model development 3.1 Analysis method}

Numerical model is developed using ANSYS 17.2 [20] to determine the plate buckling resistance of orthotropic plates. The applied model is a full shell model using fournode thin shell elements. The model is limited to one panel of the entire steel bridge between transverse stiffeners subjected to pure compression, as shown in Figs. 2-3. The numerical model has pinned supports at all four edges. Two calculations are made on each model, at first only the vertical displacements are restricted along the longitudinal edges, after it both the vertical and lateral displacements. The reason of the different support conditions is the possible difference between the effect of adjacent plates on the buckling behavior. If the panel is supported by vertical 


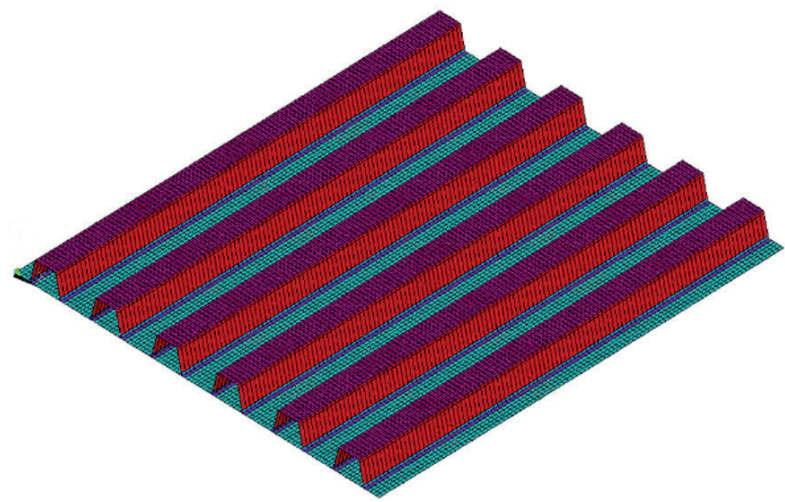

Fig. 3 Numerical model of the analyzed plate

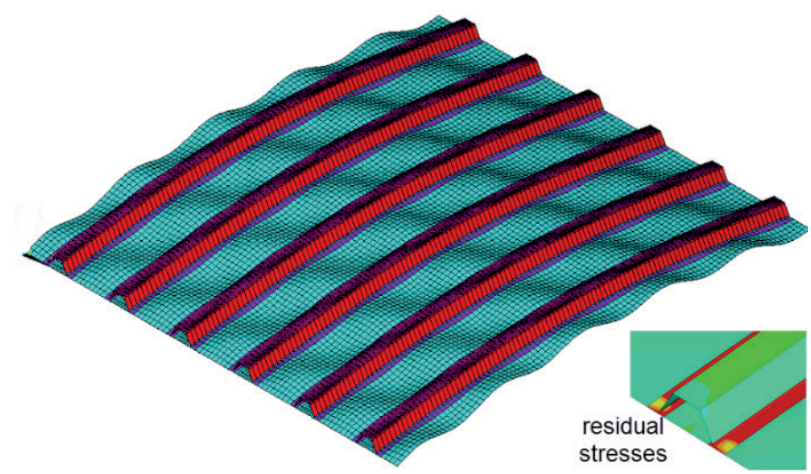

Fig. 4 Geometrical imperfections (increased scale) and residual stresses

web plates, they can provide only vertical, but no horizontal supports. However, if inclined webs or adjacent lower flange parts gives the support of the plate, they can provide both vertical and horizontal supports. No rotational supports are applied in the current study; only hinged boundaries are used. From the two calculation results the minimum ultimate load is considered as the compression resistance of the investigated panel. The load is applied as a uniformly distributed load on the plate and longitudinal stiffeners, which are considered as one cross section. This loading condition ensured centric load to the plate.

Two types of analysis are carried out on the numerical model: (i) bifurcation analysis (GNB) to determine the critical compression stress of the investigated panel and (ii) GMNI analysis to determine the ultimate buckling resistance. For the buckling resistance determination geometrical and material nonlinear (GMNI) analysis is used considering initial geometric imperfections and residual stresses. Full Newton-Raphson approach is used in the nonlinear analysis with $0.1 \%$ convergence tolerance of the residual force based Euclidian norm. Mesh sensitivity analysis is conducted to ensure the accuracy of the numerical model. Convergence study showed that all the sub-panels should be discretized by at least 5 elements along their cross-section.

\subsection{Material model and imperfections}

Linear elastic - hardening plastic material model using von Mises yield criterion is applied. The material behaves linearly elastic up to the yield strength $\left(f_{y}\right)$ by obeying the Hooke's law with Young's modulus equal to $210000 \mathrm{MPa}$. The yield plateau is modelled up to $1 \%$ strains. By exceeding the end of the plateau, the material has an isotropic hardening behavior with a hardening modulus until it reaches the ultimate strength $\left(f_{u}\right)$ at $15 \%$ strains. In the numerical parametric study only S355 steel grade is used having nominal values for the yield and ultimate strengths.

Imperfections have an important role in the simulations, because stability problem is studied. Imperfections are applied both on the longitudinal stiffeners and on the sub-plate parts of the entire panel in accordance with the rules of EN1993-1-5 [1]. The standard allows the application of equivalent geometric imperfections, which contains the effect of geometric imperfections and residual stresses together. However, it is known, that the geometric imperfection related to plate buckling $(b / 200)$ in the EN 1993-1-5 is calibrated to the Winter curve. Therefore, its application would lead to confusing results by the check of the applicability of the Winter curve. Therefore, in the current study geometric imperfections related to manufacturing tolerances and residual stresses are applied using the following shapes and magnitudes:

- global out-of-plane imperfection of the longitudinal stiffeners with an amplitude of $A_{i m p, g}$ equal to $a / 1000$,

$$
\operatorname{imp}_{\text {glob }}(x, y)=A_{\text {imp }, g} \times \sin \frac{\pi \times y}{a},
$$

- local sub-panel imperfection with an amplitude $A_{i m p, l}$ equal to $b_{i} / 500$ (bi is the width of the sub-plates),

$\operatorname{imp}_{l o c}(x, y)=A_{i m p, l} \cdot \cos \frac{\pi \cdot x}{b_{i}} \cdot \sin \frac{\pi \cdot y}{b_{i}}$,

- residual stresses (tensile residual stresses equal by the yield strength in the welding zone and compressive residual stresses equal by $25 \%$ of the yield strength between the welding zones).

Geometric imperfections are defined by the modification of the perfect shape of the panel using sinus wave functions in both directions. Residual stresses are modelled using initial strains, as shown in Fig. 4. It is proved by several researchers in the past [23], that for longitudinally stiffened plates the direction of the applied imperfection has significant effect on the ultimate capacity of the panel. Therefore, each simulation is executed having 
imperfection directions with positive and negative sign as well. The minimum of the two calculations is considered as the ultimate resistance of the panel.

\subsection{Investigated parameter range}

The parameters varied in the numerical parametric study are the panel length $(a)$, the number of stiffeners $(n)$, the distance between the stiffeners $(w)$, plate width and thickness $\left(b, t_{p}\right)$ and the cross-section of the longitudinal stiffeners $\left(h_{s l}, t_{s l}, b_{s l, 1}, b_{s l, 2}\right)$ as shown in Fig. 2. Only trapezoidal closed section stiffeners are applied in the current research program, because these stiffeners are commonly used in bridges. The panel length $(a)$ is varied between 3000-6000 mm, the thickness $\left(t_{p}\right)$ between 14-20-25-3040-45-50-60 $\mathrm{mm}$, the number of stiffeners $(n)$ between 3-4-6-7-8-10. The sub-panel width between the stiffeners $(w)$ is changed between $250-450 \mathrm{~mm}$. The stiffener thickness $\left(t_{s l}\right)$ is varied between 3-4-5-6-8-10 mm with a cross section depth $\left(h_{s l}\right)$ of 50-75-100-150 mm. The plate lengthto-width ratio is set to $\alpha=0.9-4.0$. A total of 85 different panel geometries are studied in the current research program. It is important to mention that column-like behavior is more dominant for panels with small aspect ratio $(\alpha<1,0)$. Plate-like behavior is more dominant for panels with large aspect ratio $(\alpha>1,0)$, however it also depends on the stiffener stiffness $(\gamma)$. In case of the analyzed plates the plate-like behavior was always dominant, and the condition $\xi>1,0$ was ensured for all panel geometries. It is also known that the panel aspect ratio has large importance on the critical stress and on the buckling resistance. The numerical calculations proved that the lowest resistance can be achieved using $\alpha=1,0$; therefore, this ratio is mainly used in the executed parametric study. Structures having larger $\alpha$ values are expected to provide larger resistances leading to safe design. However, this is not always representative for the practical cases and for the demonstration of the scatter of the results if the panel aspect ratio changes, different $\alpha$ values are also used in the current investigation. The results are evaluated separately for all investigated panels (having various $\alpha$ values) and for panels having panel ratio around $1.0(0.9<\alpha<1.2)$.

\section{Results of the numerical simulations}

The aim of the numerical analysis is to determine the buckling resistance of the analyzed stiffened panels, and to compare the numerical resistances to the Winter curve. In the numerical parametric study the critical stresses related to plate-like buckling $\left(\sigma_{c r, p, n u m}\right)$ and the ultimate loads $\left(N_{u l t, p}\right)$ of all the 85 studied panels are determined and evaluated. The reduction factor based on the numerical simulations $\left(\rho_{p, \text { num }}\right)$ is calculated according to Eq. (6) based on the numerical compression resistance $\left(N_{u l t, p}\right)$, the cross-sectional area $(A)$ and the nominal yield strength $\left(f_{v}\right)$ of the plate.

$\rho_{p, \text { num }}=\frac{N_{u l t, p}}{A \cdot f_{y}}$.

The obtained failure mode for one specific case is presented in Fig. 5.

The results of all the numerical calculations are compared to the buckling curve of the EN 1993-1-5 which are presented in Fig. 6. The local slenderness ratios $\left(\lambda_{p, E N}\right)$ are calculated based on EN 1993-1-5 using the critical stress according to Annex A [1]. The buckling resistance of all the numerical calculations having various panel aspect ratios are presented by blue dots on the diagram. The results representing smaller aspect ratios $(0.9<\alpha<1.2)$ are presented by red dots. The results show, that the buckling curve of the EN 1993-1-5 provides a good approximation of the numerically calculated results. In the slenderness range of $0,6<\lambda_{p, E N}<1,5$ (mainly used in the design praxis)

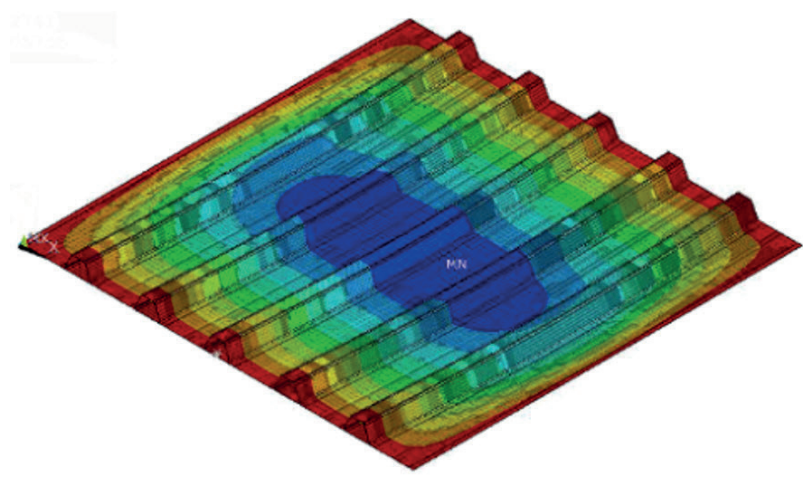

Fig. 5 Typical failure mode obtained in the numerical simulations

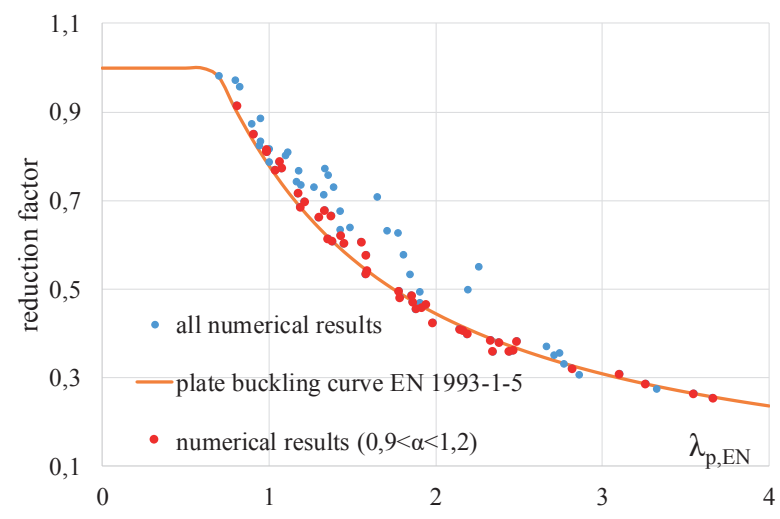

Fig. 6 Comparison of the numerical results to the buckling curve of the EN 1993-1-5 [1] using standard based slenderness ratio 


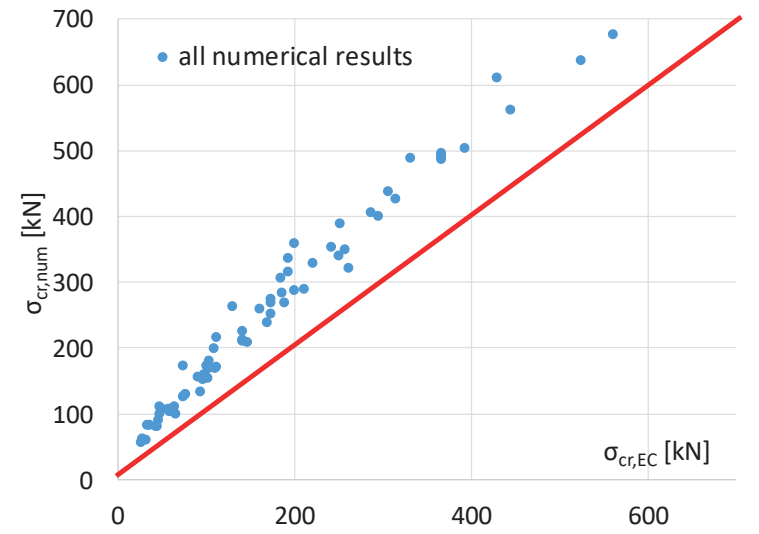

Fig. 7 Comparison of the numerical and analytical critical stresses

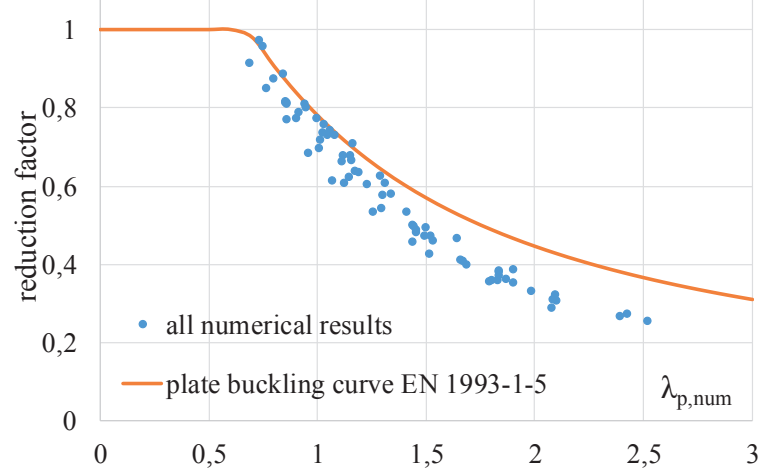

Fig. 8 Comparison of the numerical results to the buckling curve of the EN 1993-1-5 [1] using numerically computed slenderness ratio

the buckling curve is a lower bound curve of the numerical results. For higher slenderness ratio there are several points below the standard buckling curve, however the maximum difference on the unsafe side is only $4 \%$. It should be also noted that the current simulation results consider the worst case scenario of the imperfection sizes and directions. Therefore, the current simulations lead to the smallest possible resistance of real structures.

The results also prove that panels with smaller aspect ratios are closer to the buckling curve and provides smaller resistances then panels having larger aspect ratio. The resistance decrease can come from the effect of the column-like behavior or from the supporting effect of the plate itself having larger aspect ratio. The author checked that the column-like behavior has no influence in the analyzed cases and the studied panel geometries are representative for plate-like behavior.

These results also prove that for the analyzed stiffened plate geometries the buckling curve of the EN 19931-5 does not provide the mean value of the resistance, as observed for the unstiffened panels. It is rather a lower bound curve with good fit to the simulation results, therefore its consideration should differ from the unstiffened panels. However, it should be also highlighted that there are several points on the unsafe domain which could be handled by an appropriate partial safety factor. The calculated critical stresses obtained by the numerical model and calculated according to the EN 1993-1-5 Annex A are also compared and presented in Fig. 7.

The comparison shows that the tendency of the numerical and analytical results is similar. However, the analytical calculation of the EN 1993-1-5 Annex A always underestimated the critical plate buckling stress in case of the analyzed geometries. Underestimation of the critical stresses seems to be on the safe side in the design. However, if numerical models are used to calculate the critical stress, the overestimation of the critical stress can lead to underestimation of the slenderness ratio and it leads to overestimation of the buckling reduction factor. This fact was also realized by researchers in the past and therefore Martin et al. [3] proposed to neglect the torsional stiffness of the longitudinal stiffeners from the critical stress calculation, if it is determined by numerical tools. The numerical calculation results are also compared to the buckling curve, if the local slenderness ratio $\left(\lambda_{p, \text { num }}\right)$ is calculated based on the critical stresses determined by the numerical model $\left(\sigma_{c r, p, n u m}\right)$. The results are shown in Fig. 8. Based on the evaluation of the numerical simulations results it can be concluded, if the numerically computed critical stresses are used to determine the relative slenderness, the plate buckling curve of the EN 1993-1-5 does not lead to safe side resistances. Buckling behavior is closer to the buckling curve presented by Schillo et al. [7]. Results prove, if numerical model is used to calculate critical stresses, buckling curve or the critical stress calculation method should be changed, as proposed by Schillo et al. [7], or Martin et al. [3].

The simulation results are also evaluated if the critical stresses are calculated by neglecting the torsional stiffness of the stiffeners in the numerical model (Fig. 9). The same technique is used as proposed by Martin et al. [3], and the stiffener upper flange is separated into two independent parts along its midline as shown in Fig. 9. The critical stresses are recalculated on this numerical model and the buckling resistances are determined using the original continuous model. The results showed that the critical stresses decreased for the main part of the analyzed cases, and therefore the considered slenderness ratios increased. The scatter of the results also increased, all the points moved closer or above the buckling curve. However, there are still several numerical results below 
the buckling curve. The differences between the critical stresses with and without consideration of the torsional stiffness has been also investigated. The results showed that the difference between the results provided by the two numerical models are in close relation with the stiffness of the stiffeners related to the plate out-of-plane stiffness $(\gamma)$.

Increasing the value of $\gamma$ results in increase in the differences between the critical stresses obtained by the continuous and the slotted model. The relationship between $\gamma$ factor and the critical stress ratio is plotted in Fig. 10. These results mean that for panels with larger $\gamma$ value, the difference between the critical stresses will be larger and the modification in the numerical model has larger impact on the relative slenderness ratio. Therefore, the results of the panels having larger $\gamma$ values $(\gamma>5)$ are presented by red dots in Fig. 9. It can be seen, that all the points except one are located above the buckling curve of the EN 1993$1-5$ in the slenderness range of $0,6<\lambda_{p, \text { num }}<1,8$, which covers a significant part of the practical application domain.
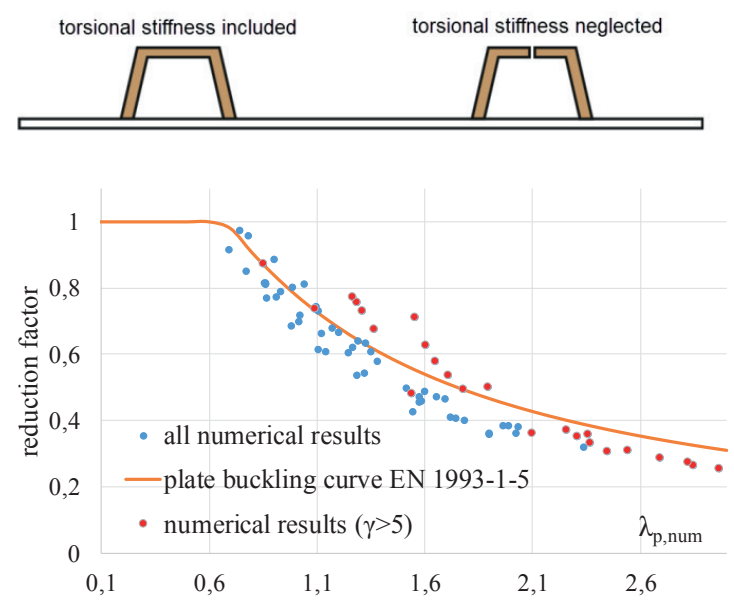

Fig. 9 Comparison of the numerical results to the EN 1993-1-5 [1] using numerically computed slenderness ratio and neglecting torsional stiffness

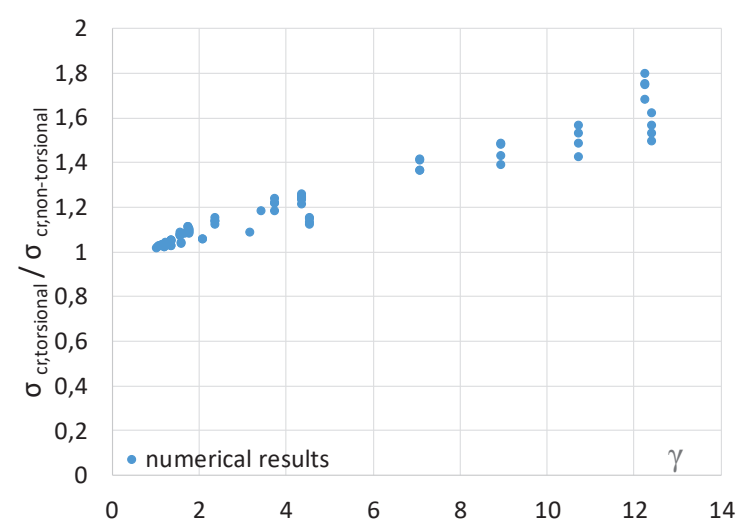

Fig. 10 Comparison of critical stresses considering or neglecting the torsional stiffness of the stiffeners
Thus this parameter range $(\gamma>5)$ is always the case of the practical civil engineering application of longitudinally stiffened plates, it can be concluded that the proposed modelling technique is applicable and provides safe side resistances for the pure plate-like behavior as well, however the scatter of the results is relatively large. Results presented on Fig. 10 also shows, that closed form equation could be given to modify the critical stresses computed by FEM models considering torsional stiffness. This equation would help designers to eliminate the torsional stiffness of longitudinal stiffeners from the calculated critical stresses without time consuming modifications of the numerical model. However, development of reliable design equation would need more numerical calculations made on plates having different longitudinal stiffeners.

Based on the numerical simulation results and the computed critical stresses it is concluded that the application of the analytical critical stresses is recommended to use in the plate-like buckling resistance calculation of panels having closed section longitudinal stiffeners. If numerical tools are applied in the design process, the torsional stiffness of the longitudinal stiffeners should be neglected as proposed by Martin et al. [3]. This modelling technique leads to reduction of the considered critical stresses and increase the obtained relative slenderness ratio. The current numerical calculations prove that both methods lead to safe side resistances using the buckling curve of the EN 1993-1-5. However, by the application of numerical tools the scatter of the results is much larger, therefore further investigation for better solution would be also required.

\section{Determination of partial safety factor}

To evaluate the accuracy and the applicability of the plate buckling curve, statistical evaluation is executed and the necessary partial safety factor $\left(\gamma_{M}^{*}\right)$ is calculated. The statistical evaluation and the determination of the partial safety factor based on a semi-probabilistic method is executed according to the recommendations of the EN 1990 Annex D [9]. For the calculation of $\gamma_{M}{ }^{*}$ the basic concept given in [4] and [21] are also applied, which considers (i) the specialties of the stability problems for steel structures, (ii) the uncertainties of the steel material properties and (iii) the differences between the mean and the applied nominal yield strength. The calculation method of the partial safety factor is summarized by Eqs. (7-9). More detailed and reliable statistical evaluation method could be also made based on Monte Carlo simulation technique to determine the partial safety factor, which is further research task of the author. 
$\gamma_{M}^{*}=\Delta k \cdot \gamma_{M}$

$\gamma_{M}=\frac{r_{k}}{r_{d}}=e^{1.4 \cdot Q}$

$\Delta k=\frac{e^{-2 \cdot Q_{f y}-0.5 \cdot Q_{f y}{ }^{2}}}{b \cdot e^{-1.64 \cdot Q-0.5 \cdot Q^{2}}}=\frac{0.867}{b \cdot e^{-1.64 \cdot Q-0.5 \cdot Q^{2}}}$.

The mean value of correction factor $(b)$ is calculated based on the comparison of the simulation results $\left(r_{e}\right)$ and the theoretical values calculated by the buckling resistance function $\left(r_{t}\right)$, according to Eq. (10).

$b=\frac{\sum r_{e, i} \cdot r_{t, i}}{\sum r_{t, i}^{2}}$.

The error term $\left(\delta_{i}\right)$ for each panels are given by Eq. (11).

$\delta_{i}=\frac{r_{e, i}}{b \cdot r_{t, i}}$

From the individual error terms, the coefficient of variation $(\mathrm{CoV})$ of the errors $\left(V_{\delta}\right)$ are determined based on Eqs. (12-15).

$V_{\delta}=\sqrt{\exp \left(s_{\Delta}^{2}\right)-1}$.

$s_{\Delta}^{2}=\frac{1}{n-1} \sum_{i=1}^{n}\left(\Delta_{i}-\bar{\Delta}\right)^{2}$.

$\bar{\Delta}=\frac{1}{n} \sum_{i=1}^{n} \Delta_{i}$

$\Delta_{i}=\ln \left(\delta_{i}\right)$.

In the equations above $\mathrm{n}$ is the number of the analyzed cases. The characteristic $\left(r_{k}\right)$ and design values $\left(r_{d}\right)$ of the resistance are calculated according to the recommendation of the EN 1990: Annex D using Eqs. (16-17), respectively.

$r_{k}=b \cdot g_{r t}\left(X_{m}\right) \exp \left(-k_{\infty} Q-0.5 Q^{2}\right)$,

$r_{d}=b \cdot g_{r t}\left(X_{m}\right) \exp \left(-k_{d, \infty} Q-0.5 Q^{2}\right)$,

where:

$g_{r t}\left(X_{m}\right)$ is theoretical resistance calculated by the resistance function using the mean values of the basic variables,

$$
\begin{aligned}
& k_{d, \infty}=3.04, \\
& k_{\infty}=1.64, \\
& Q=\sqrt{\ln \left(V_{r}^{2}+1\right)} .
\end{aligned}
$$

In the statistical evaluation process four different coefficient of variations are taken into account, variation of yield strength $\left(v_{f y}\right)$, plate thicknesses $\left(v_{t}\right)$ and plate widths $\left(v_{b}\right)$ based on the recommendations of the JCSS [22].

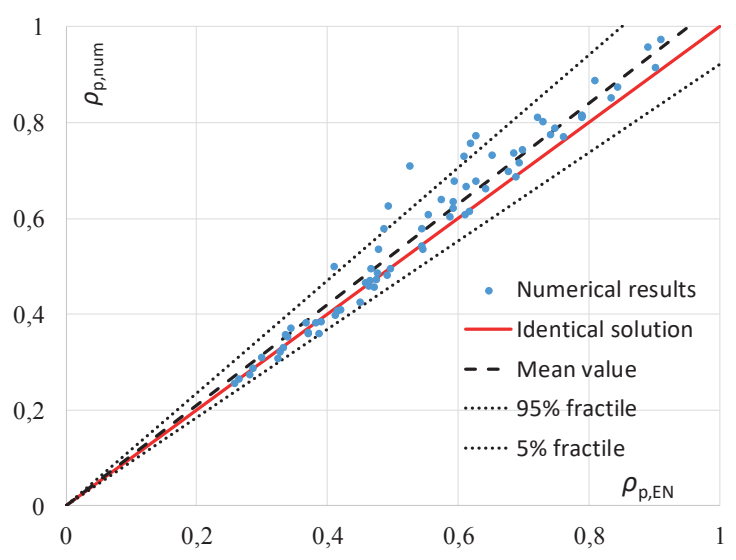

Fig. 11 Comparison of numerical and analytical buckling reduction factors

An additional factor $\left(v_{F E M}\right)$ considering the uncertainties of the numerical calculations are also added to the statistical evaluation. The following values are used as statistical parameters: $v_{f y}=0.07 ; v_{t}=0.05 ; v_{b}=0.005 ; v_{F E M}=0.02$.

The comparison of the analytical results and the numerical simulations are presented in Fig. 11. The diagram contains the results of the numerical simulations, their main value and the $5 \%$ and $95 \%$ quantile values taken from the statistical evaluation. The obtained partial safety factor based on the statistical evaluation is $\gamma_{M}^{*}=1.18$, if the plate buckling curve according to the current EN 1993-1-5 is used in the determination of the plate buckling resistance and the relative slenderness ratio is calculated using the analytical value of the critical stresses according to EN 1993-1-5 Annex A. The obtained partial safety factor is similar, or slightly larger than for another design method applied by the EN 1993-1-5 for stability design and the analyzed buckling curve is a lower bound curve for all the numerical simulation results.

Partial safety factor is also calculated for panels with panel aspect ratio between $0,9<\alpha<1,2$. These panel geometries resulted in resistances closer to the buckling curve. In case of these panels, the scatter of the results is smaller, which has positive effect on the partial safety factor $\left(\gamma_{M 1}^{*}=1.15\right)$. The partial safety factor is also determined, if the relative slenderness ratio is determined based on critical stresses using numerical tools. The evaluation provided $\gamma_{M 1}^{*}=1.46$, which value is close to the first approach of Schillo et al. [7] for unstiffened panels.

\section{Conclusions}

A comprehensive numerical parametric study is executed to investigate the plate-like buckling resistance of longitudinally stiffened orthotropic plates having closed section longitudinal stiffeners. Based on the current results it can 
be concluded that the plate buckling curve using analytical methods for the relative slenderness calculation provides a good approximation of the computed resistances for all the analyzed panel geometries. However, the obtained safety level $\left(\gamma_{M 1}^{*}=1.18\right)$ is slightly higher than the safety level of other stability design methods of the EN 1993-1-5. The numerical simulations proved that the plate buckling curve of the EN 1993-1-5 is a lower bound curve for the buckling resistance calculation of panels having closed section stiffeners in the practical slenderness range $0,6<\lambda_{p, E N}<1,5$. Therefore, this longitudinally stiffened plates are not a worst case scenario, and their behavior differ from the unstiffened panels.

However, calculation results also proved, if numerical tools are applied for the critical stress calculation and the slenderness ratio is calculated based on these values, the buckling curve overestimates the resistance and a significantly larger partial safety factor $\left(\gamma_{M 1}^{*}=1.46\right)$ would be required according to the EN 1990. If numerical model

\section{References}

[1] EN1993-1-5:2005 "Eurocode 3 - Design of steel structures - Part 1-5: Plated Structural elements", CEN, Brussels, Belgium, 2006. [online] Available at: https://archive.org/details/en.1993.1.5.2006/ page/n1 [Accessed:06.05.2019]

[2] Boissonnade, N. "ComBri: Competitive Steel and Composite Bridges by Innovative Steel Plated Structures, Final report", European Comission, Research Fund for Coal and Steel, Brussels, Belgium, Rep: RFS-CR-03018, 2007. [online] Available at: https:// www.researchgate.net/publication/263658207_Competitive_steel_ and_composite_bridges_by_innovative_steel_plated_structures_ ComBri [Accessed:06.05.2019]

[3] Martin, P.-O., Nguyen, T. M., Davaine, L. "Effect the torsional stiffness of closed-section stiffeners on plate buckling in Eurocode 3, Part 1-5", Steel Construction - Design and Research, 12(1), pp. 10-22, 2019. https://doi.org/10.1002/stco.201800001

[4] Johansson, B., Maquoi, R., Sedlacek, G. "New design rules for plated structures in Eurocode 3", Journal of Constructional Steel Research, 57(3), pp. 279-311, 2001. https://doi.org/10.1016/S0143-974X(00)00020-1

[5] Sinur, F. "Stability of longitudinally stiffened plates", presented at ECCS Technical Working Group 8.3 Meeting, Aachen, Germany, Oct. 13, 2014.

[6] Schillo, N., Feldmann, M. "Local buckling behaviour of welded box sections made of high-strength steel - Comparing experiments with EC3 and general method", Steel Construction - Design and Research, 8(3), pp. 179-186, 2015. https://doi.org/10.1002/stco.201510028

[7] Schillo, N., Taras, A., Feldmann M. "Assessment of safety factor for local buckling", presented at CEN/TC250/SC3/WG5 Meeting, Stuttgart, Germany, Febr. 26, 2016. is used for the critical stress calculation, increased partial safety factor or enhanced buckling curve should be applied. The results for this evaluation method are similar to the results presented for unstiffened girders by Schillo et al. and it could be classified as a worst case scenario.

Optional solution could be also modification of the numerical model neglecting the torsional stiffness of the stiffeners as proposed by Martin et al. [3]. The current simulations proved that for stiffeners applied in the praxis the proposed modelling technique (slitting the stiffeners along their longitudinal axis) provides safe side resistances in the practical slenderness range.

\section{Acknowledgement}

The research program was supported by ÚNKP-18-4 New National Excellence Program of Ministry of Human Capacities; and by János Bolyai Research Scholarship of the Hungarian Academy of Sciences; financial supports are acknowledged.

[8] Schillo, N., Taras, A. Feldmann, M. "Assessing the reliability of local buckling of plates for mild and high strength steels", Journal of Constructional Steel Research, 142, pp. 86-98, 2018.

https://doi.org/10.1016/j.jcsr.2017.12.001

[9] EN 1990:2002+A1 :2005 (E) "Eurocode - Basis of structural design", European Committee for Standardization, Brussels, Belgium, 2005.

[10] Kármán, T., Sechler, E. E., Donnel, L. H. "The strength of thin plates in compression", ASME, Journal of Applied Mechanics, 54(1), pp. 53-57, 1932.

[11] Timoshenko, S., Gere, J. M. "Theory of elastic stability", 2nd ed., McGraw-Hill Book Company, New York, NY, United States, 1961.

[12] Klöppel, K., Scheer, J., Möller, K. H. " Buckling stiffened rectangular plates (Volume I)" (Beulwerte ausgesteifter Rechteckplatten (Band I)), Ernst \& Sohn, Berlin, Germany, 1960. (in German)

[13] Klöppel, K., Möller, K. H. " Buckling augestefter rectangular plates (Volume II)" (Beulwerte ausgesteifter Rechteckplatten (Band II)), Ernst \& Sohn, Berlin, Germany, 1968. (in German)

[14] Yamada, Y., Watanabe, E. "On the behaviour and ultimate strength of longitudinally stiffened flanges of steel box girders", Proceedings of the Japan Society of Civil Engineers, 252, pp. 127-142, 1976. https://doi.org/10.2208/jscej1969.1976.252_127

[15] Mikami, I., Niwa, K. "Ultimate compressive strength of Orthogonally stiffened steel plates", Journal of Structural Engineering, 122(6), pp. 674-682, 1996. https://doi.org/10.1061/(ASCE)0733-9445(1996)122:6(674)

[16] Simon, J., Kemenczés, A., Vigh, L. G. "Optimal stiffener geometry of stiffened plates: Non-linear analysis of plates stiffened with flat bars under uniaxial compression", presented at Proceeding of the 7th European Conference on Steel and Composite Structures, EUROSTEEL, Naples, Italy, Sept. 10-12, 2014. 
[17] Winter, G. "Strength of thin steel plates compression flanges", Transactions of the American Society of Civil Engineers, 112(1), pp. 527-554, 1947.

[18] Bridge, R. Q., O'Shea, M. D. "Behaviour of thin-walled steel box sections with or without internal restraint", Journal of Constructional Steel Research, 47(1-2), pp. 73-91, 1998. https://doi.org/10.1016/S0143-974X(98)80103-X

[19] Pircher, M., O'Shea, M. D., Bridge, R. Q. "The influence of the fabrication process on the buckling of thin-walled steel box sections", Thin-Walled Structures, 40(2), pp. 109-123, 2002. https://doi.org/10.1016/S0263-8231(01)00055-6

[20] ANSYS® Student Community, "Ansys student version 17.2", [computer program] Available at: https://studentcommunity.ansys.com/ thread/ansys-versio-17-2-download/ [Accessed:06.05.2019]
[21] Sedlacek, G. "Report on the consistency of the equivalent geometric imperfections used in design and the tolerances for geometric imperfections used in execution", CEN/TC250 - European Committee for Standardization, Brussels, Belgium, 2010.

[22] JCSS "Probabilistic model code", Joint Committee of Structural Safety, 2002. [online] Available at: https://www.jcss.byg.dtu.dk/ publications/probabilistic_model_code [Accessed:06.05.2019]

[23] Timmers, R., Schwienbacher, M., Lang, R., Lener, G. "Proposal and validation of a simplified numerical buckling check for stiffened plated elements", presented at Proceeding of Eighth International Conference on Thin-Walled Structures, ICTWS 2018, Lisbon, Portugal, July 24-27, 2018. 